\title{
ENCONTROS E DESENCONTROS ENTRE ADOLESCÊNCIA E EDUCAÇÃO: RELATO DE PESQUISA-INTERVENÇÃO
}

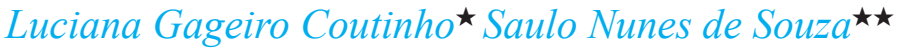 \\ Bruna Osório Oliveira $\star \star \star$
}

\begin{abstract}
Resumo
O artigo é fruto de uma pesquisa realizada na interface entre a psicanálise e a educação cuja proposta é investigar e intervir sobre a relação do adolescente com a escola hoje. Baseou-se em uma pesquisa-intervenção realizada junto a adolescentes e aos educadores que trabalham diretamente com este segmento, desenvolvida numa escola pública do estado do Rio de Janeiro, localizada no município de Niterói. O trabalho na escola se deu através da realização de oficinas oferecidas aos integrantes de um projeto para alunos com dificuldades na conclusão do ensino fundamental. A construção de categorias de análise permitiu uma organização dos dados e das falas registrados nos relatórios, facilitando a discussão teórica a partir do campo. Dentre diversas questões observadas pela pesquisa, destaca-se a dificuldade dos adolescentes em sustentar um discurso próprio e singular sobre si, o que é reforçado pela proposta da turma especial na qual estão inseridos.
\end{abstract}

Palavras-chave: adolescência; psicanálise; educação; pesquisa-intervenção.

\section{Agreements and disagreements BeTWeEn ADOLESCENCE AND EDUCATION: REPORT OF RESEARCH-INTERVENTION}

\begin{abstract}
This paper is the result of a research on the interface between Psychoanalysis and Education that proposes to investigate and intervene on the relationship teenagers have towards school nowadays. It was based upon a researchintervention conducted with teenagers and educators that work directly with that segment, within a public school in the State of Rio de Janeiro, located in the municipality of Niterói. The work at the school consisted in workshops

\footnotetext{
^ Psicóloga. Doutorado em Psicologia (Psicologia Clínica) pela Pontifícia Universidade Católica do Rio de Janeiro com bolsa-sanduíche (CNPQ) em Paris VII. Professora do Departamento de Fundamentos Pedagógicos da Faculdade de Educação da Universidade Federal Fluminense. Endereço: Universidade Federal Fluminense, Faculdade de Educação. Campus do Gragoatá Bloco D, $4^{\circ}$ andar - Departamento de Fundamentos Pedagógicos. Gragoatá - Niteroi, RJ - Brasil. E-mail: lugageiro@uol.com.br

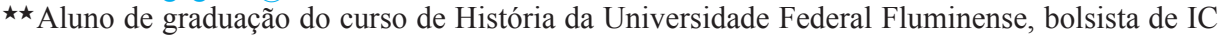
(Faperj) na pesquisa da prof ${ }^{a}$ Luciana Gageiro Coutinho.

E-mail: saulonuso@hotmail.com (Pibic) na pesquisa da $\operatorname{prof}^{a}$ Luciana Gageiro Coutinho.

E-mail:bru.osorio@hotmail.com
}

$\star \star \star$ Aluna de graduação do curso de Psicologia da Universidade Federal Fluminense, bolsista de IC
\end{abstract}


provided to those participating in a project focused on students that had trouble to complete the elementary course of studies. By creating several categories for analysis, we were able to organize the data and speech recorded in the reports, facilitating the debate on theory that departs from field work. Among the many issues noted during research, what stands out is the difficulty faced by teenagers to sustain their own and individual discourse about themselves and such difficulty is reinforced by the proposed special class in which they are enrolled.

Keywords: adolescence; psychoanalysis; education; research-intervention.

Este artigo foi elaborado a partir de uma pesquisa em andamento que incide sobre os dilemas da adolescência frente à educação no contemporâneo. Para isso trabalhamos na interface entre a psicanálise e a educação, buscando construir um diálogo que seja fecundo para as questões que a adolescência nos coloca hoje.

Partimos do pressuposto que o encontro do adolescente com a escola toma parte no trabalho subjetivo em curso na adolescência. Como bem observa Freud (1974[1914]) a respeito de sua própria adolescência no artigo Algumas reflexões sobre a psicologia do escolar, as experiências vividas na escola com os professores e com os outros alunos, ainda que remontem às relações da infância, são marcantes na definição dos rumos futuros na vida de um jovem. Com isso, Freud nos faz pensar na participação da educação e da cultura de um modo mais amplo no trabalho psíquico da adolescência. Podemos pensar que a escola enquanto meio de transmissão da cultura e de inserção na linguagem contribui para fornecer o material necessário para dar forma à fantasia, participando das novas amarrações que selam os destinos pulsionais na adolescência. Nesse sentido, estabelece-se um ponto de encontro entre a educação e a subjetivação adolescente.

Rassial (2000) define a adolescência como um momento lógico, e não cronológico, de passagem "da família ao social", de re-encontro com o Outro, ressaltando-se os elementos psíquicos e sociais envolvidos nesta operação. A adolescência implica o afastamento do Outro (simbólico) parental da infância e o encontro com o Outro da cultura, agora encarnada em novas figuras identificação e novos ideais. Mas, além disso, a adolescência diz respeito a uma mudança subjetiva traduzida no modo pelo qual o sujeito se apropria daquilo que vem do Outro e produz um discurso próprio. Assim, a adolescência reedita, como trabalha Alberti (2004), o trânsito entre alienação e separação como operações fundamentais na constituição do sujeito. Trânsito do ser olhado e ser falado pelo Outro ao poder falar e agir em nome próprio, com as necessárias renúncias que se fazem acompanhar.

A posição infantil de crença na realização do ideal do Outro cai por terra e uma nova experiência de castração deve se dar. Mas não é fácil para o adolescente abrir mão desse modo de gozo consolidado na infância, de modo que o fantasma da mortificação pelo Outro é frequente. Assim, num outro extremo, as tentativas de separar-se do Outro também estão sempre presentes. Nesse ponto, prevalece um conflito entre a subjetivação e a educação, conflito que supomos se agravar particularmente na adolescência. 
Eu acredito que seja uma situação estrutural do sujeito viver com a educação que recebeu e ao mesmo tempo contra ela. [...] Geralmente em uma família são amadas as crianças que retomam de maneira direta o discurso de seus pais. Mas todos sabem muito bem que após uma certa idade isso se transforma num sintoma bastante preocupante, e que para testemunhar sua existência será necessário que esta criança tome posição relativamente a este saber, quer dizer, se coloque em exílio com relação a este saber (MELMAN, 1994, p.32).

Tal observação feita por Melman (1994) nos faz remontar ao impossível da educação já referido por Freud (1975[1937]) e nos ajuda a pensar agora nas consequências dessa impossibilidade estrutural para a adolescência. $\mathrm{O}$ individualismo moderno acirra a exigência de trabalho psíquico feita ao jovem nesse momento de passagem, ou melhor, de exílio, já que cada vez mais solitário. Os grupos de pares são frequentemente um recurso utilizado nesse trabalho da adolescência de reapropriação das referências da cultura e de construção de novos modos de gozo. Eles são um meio de identificação e sustentação de um lugar discursivo frente ao mundo social mais amplo. Retomando Freud (1974[1913]) em Totem e Tabu, lembramos que para que a lei se instaure, assim como para que um ideal se constitua ancorado em referências de uma dada cultura - operação fundamental na adolescência - é necessário que haja uma sustentação coletiva, social, fundada em identificações horizontais entre os semelhantes, na fratria.

$\mathrm{Na}$ escola, é muito evidente o quanto o estar em grupo é importante e determinante na assunção de determinadas posições diante da escola e da sociedade de um modo geral, as quais têm suscitado muito debate e inquietação no campo da educação. Mas não há também um potencial subjetivante neste encontro do adolescente com seus pares na escola? Apostando nessa dimensão e partindo do pressuposto de que em psicanálise pesquisa e clínica caminham sempre juntas (ELIA, 2000), propomos um trabalho de pesquisa-intervenção com grupos de adolescente na escola. Utilizamos um dispositivo de investigação que consiste na realização de oficinas com adolescentes dentro de suas escolas visando a inaugurar um espaço de fala e de produção que possa ser proveitoso tanto para nossa pesquisa quanto para os jovens participantes do projeto. As oficinas, intituladas "Oficinas Imagem e Ação", têm como proposta a utilização de filmes, fotografias (da mídia ou produzidos por eles próprios) ou matérias de jornais e revistas funcionando como disparadores para a relação e a conversa com os adolescentes.

O trabalho através dessas oficinas visa a favorecer a investigação e a intervenção exatamente numa situação de sociabilidade entre os adolescentes na instituição escolar, e, ao mesmo tempo, garantir um espaço de troca diferenciado e distanciado das formas de expressão instituídas dentro da escola. A presença de alguém que seja atravessado pela psicanálise na coordenação dos grupos, diferente dos pais e dos educadores, possibilita a confrontação dos adolescentes com suas falas e atos, visando à escuta do sujeito para além do aluno. 
Nesses grupos a transferência tem um lugar fundamental. Entendemos o conceito de transferência no âmbito deste trabalho, menos enquanto repetição de um laço a uma pessoa e mais como um laço ao significante que, dirigido ao Outro/analista, carrega uma significação, um saber inconsciente, tal como acontece com o sintoma. Assim, como diz Miller (1987), a transferência é a atualização da realidade do inconsciente, do Outro que constitui o sujeito enquanto rede de significantes que promovem o desejo e os modos de gozo. Cabe a quem coordena o grupo, ao contrário de se identificar com o sujeito suposto saber, fornecendo as respostas e os significados para as questões que surgem, garantir um lugar de alteridade. Lugar para o qual as falas e os sentidos (inclusive os transferenciais) possam ser endereçadas e reapropriadas pelos sujeitos, possibilitando-lhes a produção de um saber em nome próprio. Portanto, a intervenção nesses grupos com adolescentes pressupõe que alguém, na posição de coordenador do grupo, possa sustentar um lugar de fala e acolhimento das questões aos adolescentes dentro da escola, como já tem sido feito por alguns psicanalistas hoje (GAVARINI, 2009a; GAVARINI, 2009b, LACADÉE, 1999/2000; SANTIAGO, 2008; COUTINHO; ROCHA, 2007). O método adotado nestes grupos inspira-se na "conversação", trabalhada pelos pesquisadores dos Laboratórios do CIEN (LACADÉE, 1999/2000), mas inclui a oferta de algum material ou equipamento de interesse dos adolescentes (filme, fotos, câmera) que possa funcionar como disparador para o trabalho.

\section{O DESAFio DO TRABALHO COM A TURMA "AUTONOMIA"}

Em 2009 iniciamos um contato com uma escola da rede estadual do Rio de Janeiro situada no município de Niterói. Ao apresentarmos a proposta da pesquisa à escola, foi-nos sugerido o trabalho com turmas de alunos multirrepetentes que fazem parte de um projeto novo, em andamento na instituição, proveniente de uma parceria da Fundação Roberto Marinho com a Secretaria de Estado, o "Projeto Autonomia". O trabalho com estas turmas nos pareceu interessante por incidir exatamente sobre um grupo de alunos com problemas de engajamento no sistema escolar, uma vez que nossa pesquisa incide justamente nos impasses presentes na relação entre o adolescente e a escola hoje.

O nome do projeto, "Autonomia", é inspirado em um samba de Cartola, de mesmo título, e reforçado pelos ideais de Paulo Freire (1996), no livro Pedagogia da Autonomia. Trata-se de um programa de educação baseado nos telecursos que tem por objetivo escolarizar alunos do ensino fundamental e ensino médio que estão em distorção idade-série. O projeto, desenvolvido pela Fundação Roberto Marinho e a FIESP(Federação das Indústrias do Estado de São Paulo), é oferecido pela TV, mas também em parceria com o Governo de Estado do Rio de Janeiro em algumas escolas.

Trabalharemos aqui com o material relativo a uma turma do projeto, composta por aproximadamente 25 alunos de idades variadas entre 14 e 18 anos, com a qual realizamos uma oficina ao longo de oito encontros no primeiro semestre de 2010. Os encontros aconteciam semanalmente dentro da grade horária da turma 
e na sala de aula habitual deles, tendo duração de uma hora e meia aproximadamente cada um. Esse horário foi negociado com a direção da escola e com as professoras responsáveis pela turma. Paralelamente, tivemos encontros com as duas professoras que se revezavam nas aulas com a turma do projeto, embora sem muita regularidade devido a diversas impossibilidades levantadas por elas (falta de tempo, problemas de saúde, atividades extras fora da escola, etc.). Todas as atividades realizadas na escola foram registradas através de relatórios, que serviram para a análise qualitativa feita a partir da construção de categorias (BARDIN, 1977) relacionadas às falas dos próprios adolescentes. As categorias de análise permitiram uma organização dos dados e das falas levantadas a partir do trabalho com os adolescentes, facilitando a discussão teórica a partir do campo.

De início, apresentamo-nos à turma como pesquisadores da universidade interessados em conhecer mais sobre os jovens e sua relação com a escola. Éramos três no trabalho com esta turma, sendo uma professora/coordenadora da pesquisa e dois estagiários de iniciação científica. Fizemos uma proposta a eles de, durante nossos encontros, conversarmos sobre os jovens e a escola e realizarmos algumas atividades, mediadas por fotos e filmes, que eles mesmos poderiam produzir com uma câmera que disponibilizamos para isso. Já neste primeiro dia, evidenciamos algumas marcas da transferência que deu o tom dos encontros. As expectativas em relação ao trabalho eram de "um tempo de férias", "um tempo livre", de não ter "as aulas chatas" do telecurso. Apresentaram-se a nós como "a turma de repetentes" da escola e não mostraram muito interesse em saber algo sobre nós. Apenas uma menina perguntou sobre a universidade e as relações de amizade que se pode fazer por lá. Ali entre eles, predominava o barulho, a zoação de um com o outro e a dificuldade de sustentar uma fala individual, o que se traduzia em falas como: "ele não falou, eu também não vou falar"; "deixa pra lá, eu não disse nada"; "eu quero ver as fotos porque eu quero apagar a minha". Nos poucos momentos em que conseguimos ouvir alguém individualmente, normalmente era para falar do outro, para zoar e quase nunca para falar realmente de si mesmo, havendo assim uma dificuldade muito grande de se sustentar uma fala. Pouquíssimas vezes o discurso saiu do caminho da brincadeira coletiva e se singularizou, mas alguns alunos conseguiram falar um pouco sobre a família, sobre seus sonhos, sobre problemas que tiveram ou têm na escola, mas sempre pareciam hesitar, não entrando em detalhes, respondendo como que para se livrar da obrigação.

A sequência dos encontros reforçou essa configuração. Propusemos algumas atividades em grupo, tais como a realização de um painel com fotos de jovens ou a escrita de um diálogo a partir de uma cena de sala de aula. Nas atividades em grupo, observamos a ausência de diálogo entre eles, cada um fazia alguma coisa isoladamente, sem acordos. Isso não significa que eles não falavam, o barulho era novamente uma marca do grupo. Falavam sobretudo para depreciar o que o outro fazia, sempre num tom de deboche e brincadeira bastante agressivos.

Em relação à nossa presença, predominava a indiferença ou tratamento equivalente ao utilizado na relação com as professoras: "posso beber água?"; "olha, ele está escrevendo errado"; "veja se está certo". Muitos simplesmente não se engajaram no trabalho e contribuíam para dispersar o grupo da proposta. 
Uma das alunas nos pede uma atividade que "não precise falar tanto"; outro, em resposta à ideia de fazermos um jogo, nos pergunta: "o que vamos ganhar nesse jogo?" Ao final dos encontros, era comum ouvirmos frases paradoxais como despedida, tais como: "tchau, até mês que vem", como nos disse uma adolescente ou "fiquem mais, até às cinco horas [...]", nas palavras de outra aluna.

Como entender essas demandas aparentemente tão paradoxais? Como manejar o trabalho com esta turma, diante de alguns limites colocados pela escola, tais como a impossibilidade de trabalharmos só com os alunos voluntários, que desejassem participar do projeto? Como trabalhar com a situação de uma turma cuja configuração moldada pela escola reforça nos alunos a identificação com o significante "repetente"?

O trabalho com a turma "Autonomia" foi perpassado por inúmeras interrogações, discutidas nos encontros dos grupos de pesquisa que aconteciam semanalmente e nos quais eram pensadas as estratégias para o encontro seguinte. A direção do trabalho com os adolescentes foi a de tentar confrontá-los com suas falas, atos e produções, seja nos momentos de conversar sobre o material produzido por eles coletivamente, seja no planejamento da continuidade dos encontros. Pouco a pouco fomos percebendo que as atividades que exigiam muito planejamento e organização se aproximavam demais do modelo escolar, o que esvaziava a possibilidade de um discurso próprio deles, tornando-se assim desinteressantes para nós e para eles. Assim, passamos a iniciar cada encontro retomando o que havia surgido no anterior e introduzindo como tema de trabalho as questões que surgiam ali no contato conosco.

Um dos momentos em que essa estratégia de devolver a eles as questões que apareciam nos pareceu produtiva se deu quando, em meio a uma tentativa de conversa sobre a autoridade - após a sugestão deles próprios para que fôssemos mais duros, sob o argumento de que "se deixar a gente faz bagunça", delegamos a eles a tarefa de conduzir a turma como professores. Esta proposta surpreendeu a turma que, por uns instantes, silenciou como em resposta a uma bronca. Mas, depois de nossa insistência em nos mantermos sentados, alguns passam a representar o papel de professores e, pela primeira vez, a atenção da turma toda é despertada e concentrada. As dramatizações tiveram sempre um tom de comédia e as cenas provocaram risos e participação da turma toda. De modo geral, os alunos se manifestavam muito mais pela "pose" e trejeitos do que pela fala. Surge um professor de sexologia, um professor de dança e uma professora dando explicações sobre como os homens deveriam tratar as mulheres. Chama-nos a atenção para a entrada em cena do corpo e do sexo. Será que há lugar para o desejo na rotina escolar à qual estão submetidos? Se não há, como fica a participação da escola no trabalho da nova amarração dos três registros que é exigido ao adolescente? Será que o gozo com a bagunça não expressa uma experiência do real que não encontra inscrição em outras amarrações possíveis?

As dramatizações continuaram no encontro seguinte e sugerimos fazer um pequeno filme delas com nossa câmera. Interessou-nos o fato de reforçar, com a câmera, a inauguração de um olhar Outro sobre eles, aberto às suas falas e às suas 
produções. Aparece na cena um jogo de forca proposto pela professora, onde o significante "burros" é a palavra a ser adivinhada. Não há nenhuma reação ou questionamento da turma sobre o aparecimento dessa palavra, mesmo após os instigarmos a pensar nisso. Reação semelhante se deu quando, durante a exibição dos filminhos no nosso último encontro com eles, questionamos o barulho constante que impossibilitava ouvir os diálogos de forma mais nítida. Para nossa surpresa, nem os alunos, nem a professora presente no dia, manifestaram incômodo algum com o barulho. Pelo contrário, gostaram muito de assistir aos filmes e pediram para vê-los novamente.

No que diz respeito à relação das duas professoras responsáveis pela turma com os alunos, notamos algumas diferenças no trabalho de cada uma delas. Pudemos notar isso nas conversas e contatos que tivemos com elas durante o período em que realizamos os encontros com a turma. Pareceu-nos que uma delas respondia de maneira reativa à indisciplina dos alunos, exigindo deles uma mudança de postura e afirmando, inclusive na presença de nossa equipe, que "eles não querem nada e assim não vão ser nada na vida". Já a outra professora, contou que apesar de ter tido muito dificuldade com o comportamento dos alunos no início do ano, notou uma mudança na atitude deles com o passar do tempo. Disse ter-se surpreendido com atos de carinho da turma para com ela e com o empenho deles em cuidar do ambiente e do material que fica na sala reservada para a turma. Esta professora nos pareceu mais flexível em relação às exigências do projeto, como, por exemplo, o trabalho com tele-aulas, e mais criativa no que diz respeito às atividades que propõe a eles. Entre tais atividades, destacamos a realização de entrevistas feitas pelos alunos da turma com ex-alunos do projeto "Autonomia" que já estavam no ensino médio. Essa mesma professora se integrou mais ao nosso trabalho e até aproveitou algumas das produções feitas conosco, como fotos e filmagens, para seu trabalho com a turma.

\section{Algumas articulações teóricas}

A partir da análise dos relatórios das atividades realizadas na escola, elegemos como eixo central de discussão da pesquisa a dificuldade dos adolescentes em sustentar um discurso próprio e singular sobre si. Constatamos que os adolescentes da turma com a qual trabalhamos demonstram uma impossibilidade de sair do lugar que lhes foi imposto, o lugar de "repetentes", "alunos-problema", ou ainda, "burros", nas palavras deles próprios. A proposta do "Projeto Autonomia", que pretensamente visa a incluir os alunos com problemas na adaptação escolar, criando uma turma especial para os alunos que têm uma maior dificuldade de aprender, acaba por reforçar a exclusão e o apego dos sujeitos a essa situação. Desta forma, o trabalho com a turma "Autonomia" nos faz testemunhar um mau encontro entre a escola e os adolescentes, com consequências subjetivas importantes.

À luz de Freud (1976[1921]) em Psicologia de grupo e análise do ego, vemos que um grupo se constitui na medida em que seus componentes compartilham um objeto comum, o que promove uma identificação entre seus membros e a sustentação dos laços com o grupo. Além disso, Freud observa que as carac- 
terísticas individuais muitas vezes se submetem às identificações que se dão naquele grupo, ou seja, o que é heterogêneo dá lugar a uma homogeneidade. Assim, há em todo grupo o fantasma da horda, do arcaico que se presentifica nas massas, que subsiste remontando a um modo de funcionamento narcísico e totalitário no qual não há lugar para a falta ou para as diferenças (ENRIQUEZ, 1990). Supomos que, na turma "Autonomia", podemos notar um predomínio desse modo de funcionamento narcísico e totalitário das massas. Isto se evidencia diante da dificuldade em ouvir/falar individualmente, uma vez que predominava no grupo um "barulho" oriundo de falas desconexas e simultâneas. Já no momento em que eram convocados a falar, dar opinião sobre certo assunto, encenar o papel do professor ou qualquer outro personagem, ou seja, comparecer como sujeitos, o silêncio prevalecia e as respostas muitas vezes eram esvaziadas.

Numa leitura lacaniana, podemos pensar que o convite ao gozo e à alienação foi marcante ao longo de nossos encontros com a turma. Entendendo a alienação como o sujeitar-se ao campo da linguagem, próprio do humano, em contraposição à separação que possibilita o acesso ao discurso e à posição de desejante (LACAN, 1985[1964]), não podemos deixar de notar que a oscilação desta báscula depende não somente das razões estruturais do sujeito, mas também da posição que o Outro assume no discurso social e institucional. Parece-nos que temos na turma "autonomia" uma situação de alienação instituída - cuja configuração, ironicamente; dificulta imensamente à produção de um discurso próprio, singular, por parte de cada um dos alunos. Alienação ao Outro da educação disciplinar que, paradoxalmente, invoca a "autonomia" mas dificulta, especialmente para os sujeitos participantes do projeto, a construção de seus próprios caminhos dentro da escola.

A partir disso, essa turma nos convoca a pensar sobre a indisciplina e a relação de oposição que os alunos estabelecem com a instituição educativa e os professores. Para psicanálise, como lembra Jerusalinsky (1994), disciplinar é tentar garantir que a criança ou o adolescente seja um adulto a quem nada falta, porém essa é uma tarefa impossível. Essa expectativa, por parte da sociedade, de fabricar uma criança ideal, faz com que qualquer imprevisto que surja seja considerado como um desvio em relação a uma norma. Isto é, todo imprevisto vai ser visto como um incidente da indisciplina, em vez de ser visto como marca da singularidade que habita o campo subjetivo. Sendo assim, a indisciplina diz respeito à presença do sujeito na situação educacional. Se ela não existisse, se todas as crianças fossem ideais, não haveria espaço para a invenção, mas apenas para um sujeito mortificado.

Vale evocar aqui também o pensamento de Giroux (1986) que, através de um olhar foucaultiano, trabalha com o conceito de resistência para criticar as teorias de reprodução em educação, que veem de forma unilateral a relação entre a instituição escolar - e seus representantes - e alunos dentro do processo de aprendizagem. Segundo Giroux (1986), as teorias de reprodução parecem demonstrar uma relação que vem de cima para baixo, unilateral, ignorando os mais diversos agentes que interagem no espaço escolar e no âmbito do ensino. Tais teorias parecem ignorar a possibilidade de modificação do que é reproduzido, por parte do espaço escolar e das relações que nele se desenvolvem. Assim, o autor 
critica a concepção de escola como uma instituição neutra, que separa o âmbito do poder do âmbito do conhecimento, pois considera a estrutura e ideologia dominantes como questões a serem problematizadas ao se pensar o a instituição escolar nas suas relações internas e externas.

Com base nisso, Giroux (1986) rejeita a ideia de "fracasso escolar" e se propõe a pensar a "resistência" manifesta nos alunos que não apresentam um bom desempenho escolar. Ao compartilhar da concepção foucaultiana de poder, a resistência é compreendida como uma das esferas em que o poder se manifesta dentro do espaço escolar, de ensino, mais precisamente na sala de aula. Tratase do poder que se manifesta em reação ao poder da instituição escolar e suas figuras representantes. Dessa maneira, rompe-se com a unilateralidade presente nas teorias de reprodução, enfatizando o caráter emancipatório da resistência. Tal conceito, segundo o autor, se distingue dos comportamentos e manifestações que, apesar de causarem distúrbios na atividade escolar, acabam por não produzir uma crítica, por parte dos alunos, daquilo que estaria provocando um descontentamento, levando, pelo contrário, a uma acomodação. Na visão de Giroux (1986), alguns comportamentos de oposição ao funcionamento escolar absorvem a lógica de dominação em vez de desafiá-la, e acabam por se transfigurar no oposto da resistência, na acomodação. Diferentemente, a resistência apresenta-se de forma crítica e desconstrutiva em relação àquilo a que ela faz frente, é, segundo o autor, um ato consciente de libertação.

Voltando à turma "Autonomia" e a indisciplina reinante no grupo, devemos vê-la como resistência ou como acomodação? A psicanálise talvez possa contribuir para essa discussão na medida em que parte do pressuposto de que o sujeito é sempre dividido, não é inteiramente senhor dos seus atos. Melman (1994) nos ajuda a pensar nos paradoxos da relação dos alunos com os educadores, ao afimar que a oposição da criança ou do adolescente à educação deve ser vista de um ponto de vista dialético, já que tal oposição preserva a educação recebida ao mesmo tempo que a anula. Nesse sentido, podemos dizer que a indisciplina vai contra a educação, na medida em que ela denuncia o impossível da educação, mas também podemos vê-la como algo a favor da educação, no sentido de apontar para as possibilidades do aprender preservando o sujeito e sua singularidade. Sempre haverá uma resistência em relação à educação, que não permitirá que tudo o que nos é ensinado seja apreendido, possibilitando assim que cada um possa imprimir um traço singular ao conhecimento do qual se apropria.

Considerando que todo sujeito dividido está implicado em seu ato, em tudo aquilo que faz e fala para além do que está previsto, gostaríamos ainda de pensar a indisciplina como um ato. Cabe então agora a pergunta sobre como os adolescentes da pesquisa respondem por seus atos. É possível para eles reconhecer-se nos seus atos, falar sobre eles e dar um sentido próprio a eles, para além daquele que é dado pelo discurso pedagógico? O que vimos no grupo foi muito mais uma impossibilidade de dizer de si, um dizer além do barulho coletivo, única forma encontrada por eles para falar. Notamos que esse barulho silencioso, ou esse silêncio barulhento, não parecia incomodar nem os alunos nem as professoras, mostrando assim estar presente sempre. Passar do agir (do acting out) ao ato, 
ou melhor, sustentar seu ato e sua fala em nome próprio, é uma operação cara aos adolescentes, como já apontou Lesourd (2004). Lacan definiu o acting out (LACAN, 2005[1962-1963], p. 140) como uma transferência selvagem que precisa ser domesticada para situar o Outro em seu campo. O agir na transferência consiste em um modo de responder ao Outro quando o sujeito não tem mais um hiato que o separe dele. Como observam Calazans e Bastos (2010) há no acting out uma demanda para que o Outro mantenha-se em seu campo. Isso significa que para além da alienação, a dimensão do agir na transferência comporta um apelo. Assim, o agir dos adolescentes da pesquisa nos revela novamente que, paradoxalmente, para se separar do Outro, é necessário encontrar o Outro. Num momento em que a falta falta, trata-se de tentar, com o agir, no caso em questão com o confronto, fazer furo no Outro e encontrar uma maneira de se separar dele.

Resta aos educadores pensar sobre como acolher esse apelo, sem cair numa oposição que reforçaria a alienação, mas também sem se furtar ao encontro. É interessante notar uma distinção na posição ocupada pelas duas professoras que trabalham com a turma (em dias alternados) no que diz respeito ao modo de responder à transferência a elas dirigida. A diferença no manejo da turma adotado pelas duas professoras nos remete à ideia já trabalhada por Kupfer (1995) e por Lajonquière (1996) da diferença entre o discurso pedagógico mais tradicional, que se dirige ao aluno ideal e um outro, mais próximo do discurso psicanalítico, marcado pela falta e pelo impossível da educação. No caso da professora que teve mais sucesso na relação com os alunos, de fato, podemos identificar o discurso de um mestre não-todo, que sustenta seu lugar e seu valor na transmissão, sem identificar-se ao lugar de todo saber que implicaria num embate com os adolescentes. Desta maneira, talvez essa professora tenha facilitado a circulação discursiva e desejante dos alunos, de forma que o saber por ela transmitido tenha tido valor, não de coerção, mas de oferta de significantes para que o sujeito adolescente possa deles se apropriar na produção de um discurso próprio.

\section{REFERÊNCIAS}

ALBERTI, S. O adolescente e o Outro. Rio de Janeiro: J. Zahar, 2004.

BARDIN, L. Análise de Conteúdo. Lisboa: Edições 70, 1977.

CALAZANS, R.; BASTOS, A. Passagem ao ato e acting out: duas respostas subjetivas. Fractal: Revista de Psicologia, Niterói, RJ, v. 22, n. 2, p. 245-256, maio/ago. 2010.

CARTOLA. Autonomia. Intérprete: Cartola. In: CARTOLA. Coleção Eldorado: Cartola. [S.1.: s.n], 1998. 1 CD. Faixa 2.

COUTINHO L. G, ROCHA, A. P. R. Grupos de reflexão com adolescentes: elementos para uma escuta psicanalítica na escola. Psicologia Clínica, Rio de Janeiro, v. 19, n. 2. p. 71-85, 2007. 
ELIA, L. Psicanálise: clínica e pesquisa. In: ALBERTI, S.; ELIA, L. (Org.). Clínica e Pesquisa em Psicanálise. Rio de Janeiro: Marca D’água, 2000. p. 2033.

ENRIQUEZ, E. Da Horda ao Estado: psicanálise do vínculo social. Rio de Janeiro: J. Zahar, 1990.

FREIRE, P. Pedagogia da Autonomia: saberes necessários à prática educativa. São Paulo: Paz e Terra, 1996.

FREUD, S. Totem e Tabu (1913). In:__. Obras Psicológicas Completas de Sigmund Freud. Rio de Janeiro: Imago, 1974. v. 13, p. 13-197. Edição Standard Brasileira.

FREUD, S. Algumas reflexões sobre a psicologia do escolar (1914). In: Obras Psicológicas Completas de Sigmund Freud. Rio de Janeiro: Imago, 1974. v. 13, p. 281-284. Edição Standard Brasileira.

FREUD, S. Psicologia de grupo e análise do ego (1921). In: . Obras Psicológicas Completas de Sigmund Freud. Rio de Janeiro: Imago, 1976. v. 18, p. 89-179. Edição Standard Brasileira.

FREUD, S. Análise terminável e interminável (1937). In: . Obras Psicológicas Completas de Sigmund Freud. Rio de Janeiro: Imago, 1975. v. 23, p. 239-288. Edição Standard Brasileira.

GAVARINI, L. Como os adolescentes da periferia (se) falam? Jogos na forma de se endereçar aos pesquisadores. Estilos da Clínica, São Paulo, v. 14, n. 27, p. 48-82. 2009a.

GAVARINI, L. Des groupes de parole avec les adolescents :à la recherche d'une parole "autre". Cliopsy, [S.1.], n. 1, p. 51-68. 2009b.

GIROUX, H. Teoria Crítica e Resistência na Educação. Petrópolis: Vozes, 1986.

JERUSALINSKY, A. Apesar de você amanhã há de ser outro dia. In: Educa-se uma criança?. Porto Alegre: Artes e Ofícios, 1994. p. 13-23.

KUPFER, M. C. Freud e a Educação: o mestre do impossível. São Paulo: Scipione, 1995.

LACADÉE, P. De la norme de la conservation au détail de la conversation. In: LACADÉE, P.; MONNIER, F. (Org.). Le Pari de La Conversation. Paris: Institut du Champ Freudien/CIEN (Centre Interdisciplinaire sur l'Enfant), 1999/2000. p. 5-13. 
LACAN, J. O Seminário: os quatro conceitos fundamentais da psicanálise (1964). Rio de Janeiro: J. Zahar, 1985. Livro 11.

LACAN, J. O Seminário: a Angústia (1962/1963). Rio de Janeiro: J. Zahar, 2005. Livro 10.

LAJONQUIÈRE, L. A criança, sua (in) disciplina e a psicanálise. In: AQUINO, J. (Org.). Indisciplina na Escola: alternativas teóricas e práticas. São Paulo: Summus, 1996. p. 25-37.

LESOURD, S. A construção adolescente do laço social. Petrópolis: Vozes, 2004.

MELMAN, C. Sobre a educação das crianças. In: JERUSALINSKY, A. (Org.). Educa-se uma criança? Porto Alegre: Ares e Ofícios, 1994. p 31-40.

MILLER, J. Percurso de Lacan: uma Introdução. Rio de Janeiro: J. Zahar, 1987.

RASSIAL, J. O Adolescente e o Psicanalista. Rio de Janeiro: Companhia de Freud, 2000.

SANTIAGO, A. L. O mal-estar na educação e a Conversação como metodologia de pesquisa: intervenção em Psicanálise e Educação. In: CASTRO, L. R; BESSET, V. L. (Org.). Pesquisa-Intervenção na Infância e Juventude. Rio de Janeiro: Nau, 2008. p.113-131.

Recebido em: 10 de janeiro de 2011 Aceito em: 04 de abril de 2012 


\begin{tabular}{|c|c|c|c|c|c|c|c|}
\hline Edicão & guivo & Títuln & Página & Parágrafo & Jinha & selêt & Ieia-se \\
\hline 4n2 (2012) & v24n2a08 & Encontros e desencontros entre adolescentes e & 341 & $* * *$ & Autores & Luciana Gageiro Coutinho* Saulo Nunes Ramos** Bruna & Luciana Gageiro Coutinho* Saulo Nunes de Souza** \\
\hline
\end{tabular}

